European Association for the

Development of Renewable Energies,

Environment and Power Quality (EA4EPQ)
International Conference on Renewable Energies and Power Quality (ICREPQ’11)

Las Palmas de Gran Canaria (Spain), 13th to 15th April, 2011

\title{
INVESTIGATION INTO HARMONICS OF LVDC POWER DISTRIBUTION NETWORK USING EMTDC/PSCAD SOFTWARE
}

\author{
Andrey Lana, Tero Kaipia and Jarmo Partanen
}

\author{
Department of Electrical Engineering \\ Lappeenranta University of Technology \\ Lappeenranta, 53851 Finland \\ e-mail: name.surname@lut.fi
}

\begin{abstract}
The paper focuses on the investigation of low voltage direct current (LVDC) power distribution network harmonic content. For investigation electromagnetic transient simulation environment PSCAD/EMTDC is used. In the paper, the frequency content of voltages and currents in the LVDC network is presented. Dependence on the power quality of the feeding medium voltage (MV) network of the LVDC network configuration is shown and discussed. In addition, impact of distribution of load across bipolar DC network load on MV network power quality is considered. Model of the LVDC power distribution network is created in PSCAD/EMTDC environment to carry out the above mentioned analyses.
\end{abstract}

\section{Keywords}

LVDC, dc power system, PSCAD, harmonic content, power quality

\section{Introduction}

The LVDC power distribution network concept is presented in Fig. 1. The main objectives behind the development of the LVDC network have been to; (1) improve the power quality and supply security experienced by the electricity end-users, (2) improve the economy of the power distribution, (3) provide flexible and robust coupling point for small scale generation, and (4) develop infrastructure for interactive and intelligent distribution network [1], [2]. The development of the LVDC network was started 2005 in Finland. DC solutions with somewhat similar properties and sharing some of the same objectives have been introduced also in [3], [4], [5], [6].

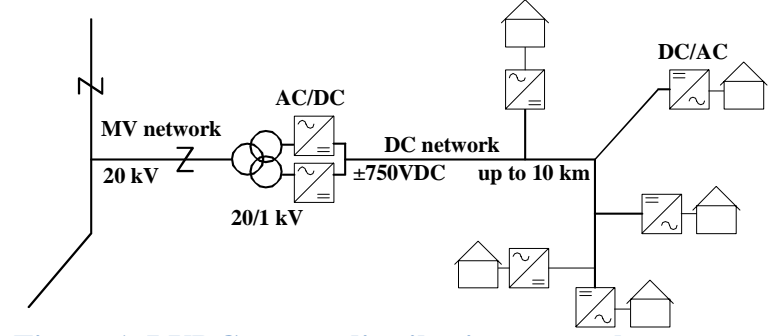

Figure 1. LVDC power distribution network

Roughly speaking the basic ideas of the LVDC network considered in this paper are to reduce the length and complexity of MV networks by increasing the transmission capacity of the low voltage networks, to use power electronics for local power flow and quality control and enable sophisticated network protection and management methods based on ICT solutions integrated into the converters of the LVDC network [7].

Power quality of MV network relates continuous state distortions and power system harmonics are continuous state problem. Power electronic load of LVDC power distribution network create harmonic pollution in DC network. In details customer inverters pollute DC network and LVDC network front-end rectifier pollute MV network. The DC network harmonic pollution is mitigating to MV network affecting MV network power quality and creates additional losses in transformer and in MV distribution network.

In the LVDC distribution network the dc network is powered by a frond-end rectifier. In simplest configuration with directional power flow, the front-end rectifier consists of two six pulse thyristor bridges connected to bipolar dc power distribution network with common zero potential. Thyristor bridges powered by phase shifting transformer with 2 secondary windings form then a 12-pulse rectifier. The customer-end inverters loading the dc system are powered from the bipolar dc power distribution network. Both one and three phase inverters can be used to energise end-customer's ac network. Inverters are mainly connected between the zero pole and plus or minus dc pole due to high \pm 750 VDC voltage used in the LVDC network. According to the basic LVDC concept, the whole LVDC network is owned by the local distribution company and the connection point of customers is at ac side of the inverter devices. In some special cases the customer's coupling point can also be located in dc side, but that situation will not be considered in the proposed paper.

The converters of the LVDC network generate versatile harmonic currents and voltages to distribution system. The distortion of voltages and currents cause extra losses in system components. The voltage distortion in MV ac network may also cause disturbance for customers connected directly to the ac system (on traditional way) and electromagnetic interferences disturbing distribution 
line carrier (DLC) signals and other communication solutions.

When the load is balanced across the bipolar DC network, fed by the 12-pulse thyristor bridge, the low-order harmonics are cancelled due to the phase shift between secondary windings of the transformer. In this case current harmonics order of $h=12 k \pm 1$ are present on the MV network side of the double tier transformer. When DC network load is unbalanced, current harmonics order of $h=6 k \pm 1$ are drawn from the feeding MV network. On transformers secondary windings current harmonics of $h=6 k \pm 1$ are produced by the 6 pulse bridges. On bipolar dc network side rectifier produce harmonics of order $h=6 k$ to the pole voltage. Harmonics of order $h=2(100 \mathrm{~Hz})$ and switching frequency harmonics are excited to DC network by the customer-end inverters. If not damped in the dc network, these inverter origin harmonics can also be detected on the rectifier dc terminals and are transferred to the MV network as well. To avoid problems caused by the harmonics and to fulfil the requirements of standardization, filtering is needed.

The simples filter applicable in the dc network is a capacitor installed between the dc poles. Harmonic contents of network current and voltage are affected by capacitors size and placement. Furthermore, the size and location of the capacitors affect on the power losses in the dc network and feeding MV network. Thus, dimensioning the capacitors requires knowledge of the frequency contents of the network voltages and currents and also knowledge how changes in the network affect on the waveforms. Requirements set in standardisation [IEC60364] for dc voltage fluctuation and dc network stability conditions [8] have to be satisfied. When considering the power quality, also the supply security has to be taken into account.

Capacitors installed on the dc side of the rectifier are commonly dimensioned based on the requirements to range the voltage fluctuation in the dc network. Similarly, the dc side capacitors of the inverters are dimensioned to meet the voltage fluctuation requirements. Minimum sizes of the capacitors are in this case calculated from rated power of the converters. The capacitors can also be dimensioned to satisfy power demand during momentary interruptions. In Finland, the power quality is considered in the regulation of distribution business through so called customer interruption costs. Each interruption has therefore an effect on the revenue of a distribution company in similar manner with the system losses. As increasing the size of the capacitors increase the investment costs, it is possible to find optimal capacitor sizes and locations through economical optimisation.

\section{THE LVDC NETWORK MODEL VALIDATION}

Validated system model in PSCAD/EMTDC environment enables analysis of harmonic content and mitigation of harmonics from DC side to MV network AC side. Harmonic content of network current and voltages can be determined and effect of system configuration on MV network power quality can be analysed. Based on simulations it is possible to select the most remarkable harmonic frequencies and develop dimensioning guidelines, for instance, for the capacitors. Moreover, the frequency contents also have to be known in planning of LVDC distribution networks to allow the technoeconomical design of network structures.

The PSCAD/EMTDC model was verified with respect to measurements on laboratory prototype installation of the LVDC network. Versatile measurements have been done and compared with simulation results. Fig. 2 presents the comparison of low order harmonic frequencies in the LVDC network determined with simulation model and measurements.

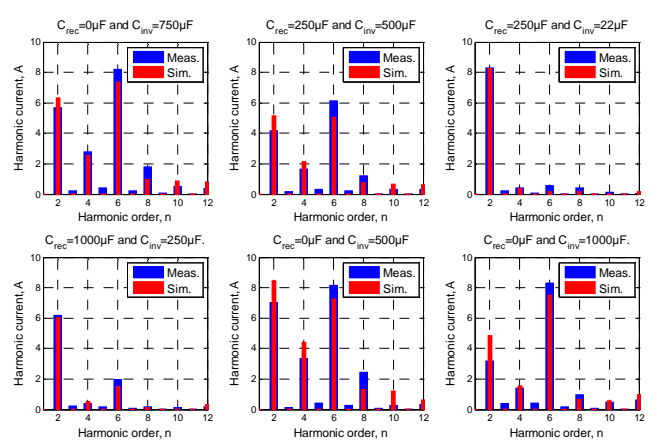

Figure 2. Comparison of DC network current harmonic contents for different system configurations. (blue measurements, red - simulations)

More detailed verification of the LVDC network model is presented in [9].

\section{THE LVDC NETWORK SIMULATION}

The model of the LVDC network with 20/0.562/0.562kV $0.1 \mathrm{MVA}$ transformer, two six-pulse thyristor rectifiers, bipolar DC network (0.9km AXMK 3x95) and 3 phase inverters (40kVA), under unbalanced load conditions (13 $\mathrm{kW}, 6 \mathrm{~kW}, 6 \mathrm{~kW}$ per A, B, C phase), on each pole is created in PSCAD environment for the harmonic investigation.

The $20 \mathrm{kV}$ MV network is formed by $20 \mathrm{~km} \mathrm{Al} / \mathrm{Fe} 85 / 14$ Pigeon conductor. MV network is feed from $\mathrm{HV} / \mathrm{MV}$ voltage transformer, with rated power 16MVA and rated voltage $110 / 21 \mathrm{kV}$. HV network is modelled as $110 \mathrm{kV}$ voltage source with $\mathrm{S}_{\mathrm{k}}=1000 \mathrm{MVA}$.

The DC network DC capacitance is chosen by dimensioning guidelines [9]. The peak load condition, the asymmetrical load condition and the unbalanced load condition of the LVDC network are simulated to provide view on MV network and LVDC network harmonics. Ripple filtering by installation of DC reactor on neutral conductor of DC network is considered and impact on MV network power quality is measured. For each simulation case harmonic content and power losses are determined. Power quality of MV network is measured by calculating voltage total harmonic distortion (THDV) and current 
total demand distortion (TDDI) on network point of common coupling (PCC). PCC assumed to be on primary windings of LVDC network transformer. In the model three phase short-circuit current of the MV network is $\mathrm{I}_{\mathrm{sc}}=1 \mathrm{kA}$ and maximum demand current of the LVDC network is $\mathrm{I}_{\mathrm{L}}=3 \mathrm{~A}$. To analyse dependence between network condition and harmonic content along with power quality, simulations are divided by different cases.

Case 0: The bipolar DC network is symmetrically loaded. Load of each 3 phase inverter is balanced (13 kW on each phase). Phase shift between inverters reference phases on bipolar poles is 45 degrees.

Case 1.x: In this case effect of phase difference on harmonics and power quality is measured. The bipolar DC network is symmetrically loaded. Load of each 3 phase inverter is unbalanced (13 kW, $6 \mathrm{~kW}, 6 \mathrm{~kW}$ per A, B, C phase).

Case 1.1. Phase shift between inverters reference phases on bipolar poles is 0 degrees.

Case 1.2. Phase shift between inverters reference phases on bipolar poles is 90 degrees.

Case 2.x: In this case effect of capacitance dimensioning on harmonics and power quality is measured. By comparison of results from case 1.1 and case 2.1, the effect of bipolar DC network load asymmetry on harmonics and power quality can be analysed. Load of positive pole inverter is unbalanced $(13 \mathrm{~kW}, 6 \mathrm{~kW}, 6 \mathrm{~kW}$ per $\mathrm{A}, \mathrm{B}, \mathrm{C}$ phase) and load of negative pole inverter is $10 \%$ of positive. Phase shift between inverters reference phases on bipolar poles is $45 \mathrm{deg}$.

Case 2.1: The DC network DC capacitance is chosen by dimensioning guidelines [9].

Case 2.2: The DC network DC capacitances are double sized.

Case 3.x. In this case effect of system configuration (addition of DC reactor on neutral wire) on harmonics and power quality is measured. The DC reactor is installed on the DC network neutral wire at rectifier terminals. Phase shift between inverters reference phases on bipolar poles is $45 \mathrm{deg}$.

Case 3.1. The bipolar DC network is symmetrically loaded. (inverter load is unbalanced)

Case 3.2. The bipolar DC network is symmetrically loaded. (3 phase inverter loads is balanced)

Case 3.3. The bipolar DC network is highly asymmetrically loaded. Network positive pole load is $100 \%$ and negative pole load is $10 \%$.

Results of the simulation and calculations for the cases described above are presented in the table 1. Conclusions, based on the simulation results, are provided below.

\section{OUTCOME OF THE SIMULATIONS}

Relative phase shift between DC network loads

In the LVDC network with common neutral conductor, the inverters placed on separate poles of bipolar network will draw the same current $(100 \mathrm{~Hz}$ harmonic) if the relative phase between them is $0^{\circ}$ or $180^{\circ}$, causing absence of $100 \mathrm{~Hz}$ harmonic in neutral wire. Other relative phase shift will create $100 \mathrm{~Hz}$ harmonic component in neutral conductor of DC network. $100 \mathrm{~Hz}$ harmonic presented in DC network is transferred to transformer AC side as third harmonic. Therefore phase shift between loads has an affect on among of third harmonic current in transformer windings. Also phase shift has an effect on fundamental frequency losses in transformer. Results show that $90^{\circ}$ phase shift reduced $150 \mathrm{~Hz}$ component on secondary and primary windings of transformer. Current harmonic distortion in this case is lower than in case when relative phase is zero degrees.

\section{Dimensioning of the LVDC network DC capacitors}

Installation of the twice oversized DC capacitors reduces among of harmonics and harmonic losses in the DC network, but do not increase much transformer losses. Because change in current total demand distortion is insignificant, doubling capacitance sizes have not much effect on MV grid power quality.

\section{Use of DC reactor}

The installation of $10 \mathrm{mH}$ DC reactor on neutral conductor of DC network at rectifier DC terminals is suppressing $300 \mathrm{~Hz}$ harmonic ripple and greatly reduce harmonic losses in DC network.

\section{Network Power Quality}

Voltage distortion limits [IEEE Std 519-1992] are meet by the simulated network in all cases. Current Distortion limits provided by [IEEE Std 519-1992] and suggested by Finnish Electricity Association SENER are applied to simulated LVDC network. Network short circuit ratio of simulated network is $\mathrm{I}_{\mathrm{sc}} / \mathrm{I}_{\mathrm{L}}=333$. Current distortion limits for this ratio are TDD lower than 15\% and amplitude of current harmonics to up to 11 lower than $12 \%$. Simulation results showed that current harmonic distortion limits can be meet by installation of DC reactor.

\section{Power Losses}

Harmonics are creating additional power losses in DC network and transformer. Suppression of harmonics in DC network by passive or active filtration will reduce harmonic power losses in network. 
Table 1. Case simulation results

\begin{tabular}{|c|c|c|c|c|c|c|c|c|c|}
\hline \multirow{2}{*}{\multicolumn{2}{|c|}{ CASE }} & $\mathbf{0}$ & 1.1 & 1.2 & 2.1 & 2.2 & 3.1 & 3.2 & 3.3 \\
\hline & & & \multicolumn{2}{|c|}{ Phase shift } & \multicolumn{2}{|c|}{ DC capacitors } & \multicolumn{3}{|c|}{ DC Reactor } \\
\hline \multicolumn{2}{|l|}{$\mathrm{P}_{\text {load }}, \mathrm{kVA}$} & 80 & 55 & 55 & 30 & 30 & 55 & 80 & 30 \\
\hline \multicolumn{10}{|c|}{ DC network harmonics $(\mathrm{n} * 50 \mathrm{~Hz}), \mathrm{A}$} \\
\hline \multirow{7}{*}{$\begin{array}{c}\mathrm{DC}_{\mathrm{p}}, \mathrm{A} \\
\text { (current harmonic } \\
\text { content of the } \\
\mathrm{DC} \text { network } \\
\text { positive pole } \\
\text { conductor) }\end{array}$} & 1 & 2.8 & 3.8 & 3.5 & 3.9 & 3.5 & 4 & 2.8 & 3.4 \\
\hline & 2 & - & 5.2 & 5.2 & 6 & 3.9 & 6.8 & - & 4.6 \\
\hline & 3 & 1.77 & - & - & - & - & - & 2.1 & - \\
\hline & 4 & - & 2.2 & - & - & - & - & - & - \\
\hline & 6 & 22.8 & 15.6 & 15.7 & 12.1 & 9.8 & - & 2 & 1.2 \\
\hline & 9 & 0.9 & - & - & - & - & - & 1.3 & - \\
\hline & 12 & - & 0.8 & 0.9 & - & - & 1.4 & 1.4 & 0.9 \\
\hline \multirow{5}{*}{$\begin{array}{c}\mathrm{DC}_{\mathrm{n}}, \mathrm{A} \\
\text { (current harmonic } \\
\text { content of the DC } \\
\text { network neutral } \\
\text { conductor) }\end{array}$} & 1 & - & - & - & 2.6 & 2.5 & - & - & 1.1 \\
\hline & 2 & - & - & 10.1 & 6.2 & 4.4 & 5.9 & - & 4.1 \\
\hline & 3 & 3.4 & - & - & - & - & - & 3.9 & 0.8 \\
\hline & 4 & - & 4.6 & - & - & - & - & - & - \\
\hline & 6 & 44.1 & $\begin{array}{l}30.8 \\
\end{array}$ & 31.3 & 15.7 & 6 & - & 2 & 1.3 \\
\hline \multicolumn{10}{|c|}{ Transformer secondary windings current (phase A) harmonic, \% of $I_{1}$} \\
\hline \multirow{8}{*}{$\begin{array}{l}\text { Current harmonic } \\
\text { content, } \\
\text { DELTA windings, } \\
\% \text { of } I_{1}\end{array}$} & 2 & 7.6 & 9.9 & 8.25 & 10 & 8.8 & 8.3 & 5.1 & 7.6 \\
\hline & 3 & 0.3 & 10 & 10.8 & 17.5 & 4 & 17.4 & 0.1 & 4.3 \\
\hline & 5 & $\begin{array}{l}68.2 \\
\end{array}$ & 76.7 & 76.5 & 68 & 66 & 20.6 & 20.2 & 23 \\
\hline & 7 & 44.6 & 45.8 & 49 & 36.8 & 36 & 14.9 & 13.9 & 14.5 \\
\hline & 11 & 6.1 & 11.7 & 13.6 & 10 & 9.7 & 12.6 & 11.1 & 11.3 \\
\hline & 13 & 3.1 & 3.6 & 1.6 & 5.8 & 8 & 5.6 & 4.5 & 5.1 \\
\hline & 17 & 4.8 & 10 & 9 & 5.2 & 4.6 & - & - & - \\
\hline & 19 & 2.2 & 5.8 & 5 & 2.5 & 3.9 & - & - & - \\
\hline \multirow{8}{*}{$\begin{array}{l}\text { Current harmonic } \\
\text { content, } \\
\text { WYE windings, } \\
\% \text { of } I_{1}\end{array}$} & 2 & 6.1 & 8.1 & 5.2 & $\mathrm{x}$ & $\mathrm{X}$ & 9.9 & 5.5 & $x$ \\
\hline & 3 & 0.14 & 22.1 & 4.7 & $\mathbf{x}$ & $\mathbf{x}$ & $\begin{array}{l}16.2 \\
\end{array}$ & 0.5 & $\mathbf{x}$ \\
\hline & 5 & 68.5 & 76 & 68.3 & $\mathbf{x}$ & $\mathbf{x}$ & 26.7 & 21 & $\mathbf{x}$ \\
\hline & 7 & 45 & $\begin{array}{l}46.8 \\
\end{array}$ & 47.2 & $\mathbf{x}$ & $\mathbf{x}$ & 19.2 & 13.2 & $\mathbf{x}$ \\
\hline & 11 & 6.5 & 11.9 & 7.4 & $\mathrm{x}$ & $\mathrm{x}$ & 15.7 & 11 & $\mathrm{x}$ \\
\hline & 13 & 2.9 & 3 & 5.2 & $\mathrm{x}$ & $\mathrm{x}$ & 5.9 & 4.5 & $\mathrm{x}$ \\
\hline & 17 & 4.9 & 9.5 & 6.9 & $\mathrm{x}$ & $\mathrm{x}$ & - & - & $\mathrm{x}$ \\
\hline & 19 & 2.3 & 6.4 & 5.2 & $\mathrm{x}$ & $\mathrm{x}$ & - & - & $\mathrm{x}$ \\
\hline \multicolumn{10}{|c|}{ Transformer primary windings individual current distortion(phase A), \% of $\mathrm{I}_{1}$} \\
\hline \multirow{6}{*}{$\begin{array}{l}\text { Current harmonic } \\
\text { content, } \\
\text { Transformer } \\
\text { primary windings, } \\
\text { \% of } I_{1}\end{array}$} & 2 & 6.1 & 9.3 & 5.9 & 10.7 & 9.7 & 8.7 & 5.6 & 11.7 \\
\hline & 3 & - & 19 & 5.5 & 18.5 & 5.5 & 14.82 & - & 8.5 \\
\hline & 5 & - & - & 3 & 51.3 & 48 & - & - & 16.8 \\
\hline & 7 & - & - & 3.5 & 29 & 27 & - & - & 10.2 \\
\hline & 11 & 6.3 & 11.9 & 9.4 & 4.2 & 4.7 & 12.6 & 11 & 13.7 \\
\hline & 13 & 3 & 3.4 & 2.4 & 4.3 & 3.3 & 5.6 & 13.5 & 4.5 \\
\hline \multicolumn{10}{|c|}{ Power quality on network PCC (transformer primary windings) } \\
\hline \multicolumn{2}{|c|}{ TDDI, \% of $\mathbf{I}_{L}$} & 7.1 & 10.6 & 7 & 16.5 & 15.4 & 11.4 & 10 & 8.3 \\
\hline \multicolumn{2}{|c|}{ THDI, $\%$ of $\mathrm{I}_{1}$} & 9.4 & 24.6 & 13.8 & 63 & 56.8 & 22.5 & 13 & 30.2 \\
\hline \multicolumn{2}{|c|}{ THDV, \% of $U_{1}$} & 0.17 & $\mathbf{0 . 1 7}$ & $\mathbf{0 . 1 7}$ & 0.25 & 0.25 & 0.24 & 0.32 & 0.21 \\
\hline \multicolumn{10}{|c|}{ Transformer and DC Transmission Power Losses, W } \\
\hline \multicolumn{2}{|l|}{$\mathrm{P}_{\mathrm{dc} \text {, harm }}$} & 1420 & 750 & 796 & 274 & 109 & 66 & 24 & 30 \\
\hline $\mathrm{P}_{\text {tra, harm }}$ & & 143 & 72 & 77 & 55 & 50 & 24 & 25 & 11 \\
\hline $\mathrm{P}_{\mathrm{dc}}$ & & 2830 & 1275 & 1278 & 1182 & 1184 & 1331 & 2922 & 1197 \\
\hline $\mathrm{P}_{\text {tra }}$ & & 800 & 265 & 365 & 110 & 119 & 346 & 780 & 122 \\
\hline $\mathbf{P}_{\text {total }}$ & & 5200 & 2362 & 2515 & 1620 & 1462 & 1767 & 3752 & 1360 \\
\hline
\end{tabular}


Waveforms of network currents and voltages for simulation case 1.2 are presented in the figure 3 .

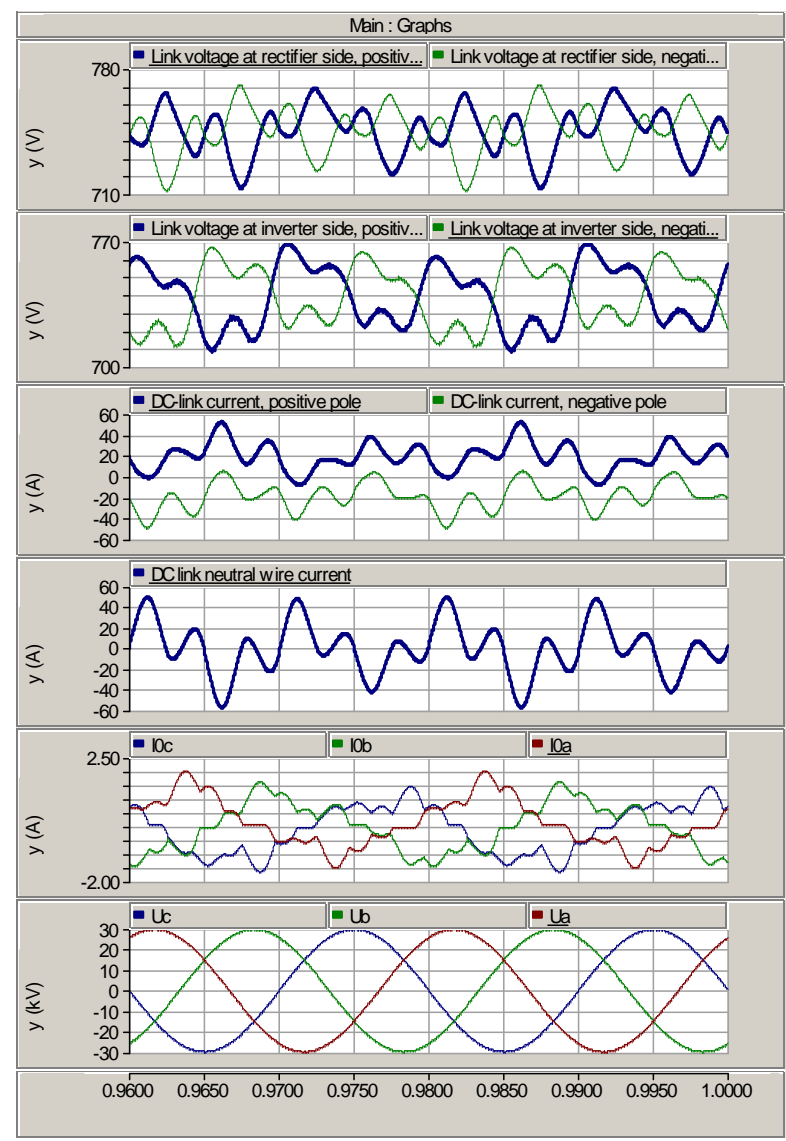

Figure 3. The LVDC network and the MV network voltages and currents.

Corresponding spectrums for network voltages and currents are presented in the figure 4.

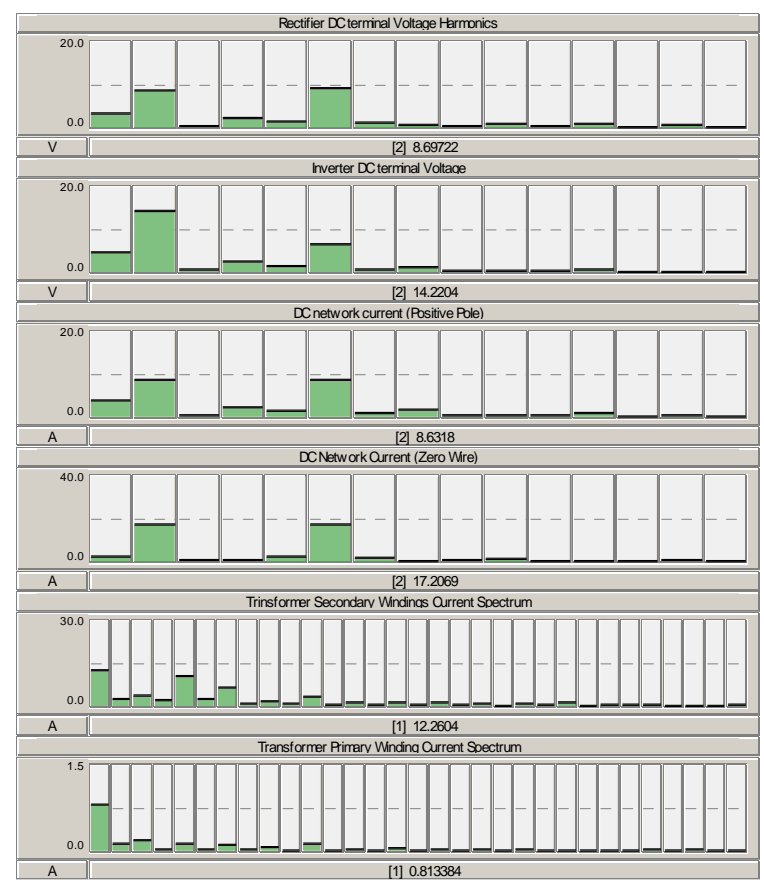

Figure 4. Spectrums of voltages and currents.
Data based models

The data based model of the network front-end rectifier is created. Data based model is useful for determination of the losses of the feeding transformer and MV network. Dependence of harmonic currents content of the balanced loading of the dc network is shown on figure 5 for MV network and figure 6 for secondary side of the transformer.

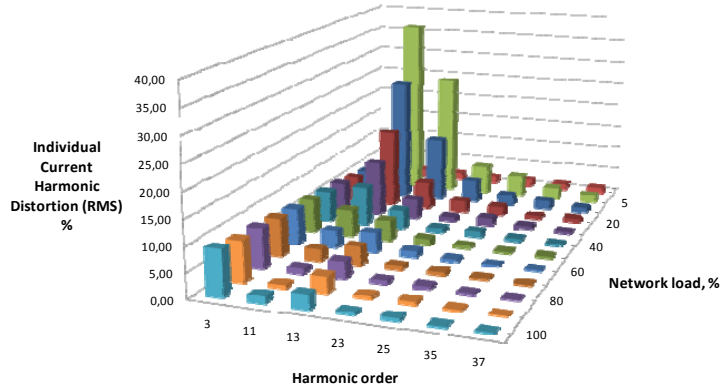

Figure 5. Individual current harmonic distortion on LVDC system transformer primary windings. (RMS, \%)

Results for total current harmonic distortion on transformer secondary windings are shown in figure 6 . In case of unbalanced DC network load, current drawn from the feeding MV network will be distorted as current on transformer secondary windings.

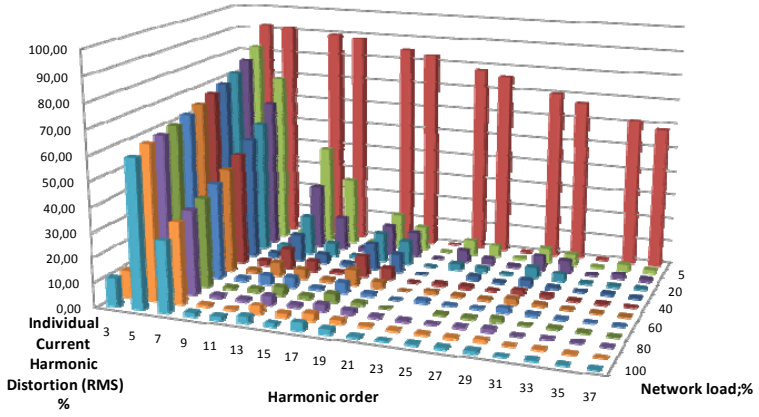

Figure 6. Individual current harmonic distortion on LVDC network transformer secondary windings (RMS, \% of $\mathrm{I}_{1}$ ).

Power quality estimate is delivered using simulations. Impact of the bipolar DC network load asymmetry on grid individual and total current harmonic distortion is determined and results are shown on figure 7.

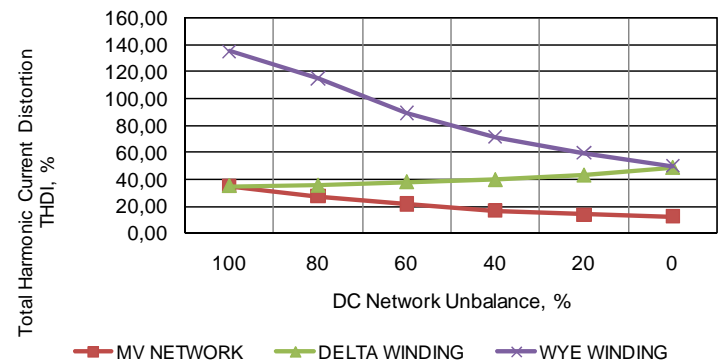

Figure 7. Total current harmonic distortion dependence on DC network asymmetry $\left(\%\right.$ of $\left.I_{1}\right)$

Power system current harmonic distortion dependence on the LVDC network load is shown on figure 8. 


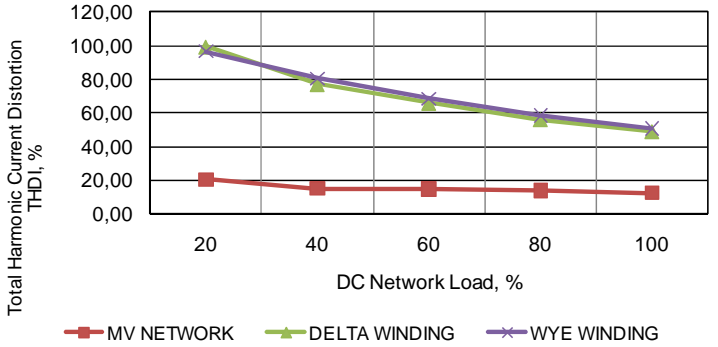

Figure 8. Total current harmonic distortion dependence on DC network load. $\left(\%\right.$ of $\left.I_{1}\right)$

Current total harmonic distortion (THD) is affected by LVDC network load condition and DC network load asymmetry. Conversion of the THD dependencies provided in figures 7 and 8 to TDD can be made using equation

$$
\mathrm{TDD}=\mathrm{THD} * \mathrm{I}_{1} / \mathrm{I}_{\mathrm{L}}
$$

where $\mathrm{I}_{\mathrm{L}}$ is maximum demand current and $\mathrm{I}_{1}$ is fundamental harmonic current when among of fundamental harmonic current can be estimated.

\section{CONCLUSION}

The investigation into power quality and harmonics of the LVDC distribution network is made using PSCAD/EMTP electromagnetic transient simulation environment. The simulation results are proved reliable by verifications with measurements on the laboratory prototype. The effect of system reconfiguration on DC network and transformer harmonic content, along with MV network power quality is determined and shown. Effect of the factors such as asymmetry across bipolar poles, relative phase between poles and network load are studied thru simulations. The simulated LVDC network is meeting voltage harmonic distortion limits and shown to be close to IEEE 519 current harmonic distortion limits. With use of the DC reactor, the simulated LVDC network is meeting current harmonic distortion limits. Harmonic analysis and calculations based on simulation results are used to provide data based models of the LVDC power distribution network components. The achieved models and results are useful, for instance, in dimensioning of the components of LVDC distribution network. The public electricity distribution network part, of which the LVDC network forms, is typically designed on minimum life cycle cost. Accurate assessment of the losses and interruptions in system is therefore in key role to avoid under or over dimensioning.

\section{REFERENCES}

[1] T. Kaipia, P. Salonen, J. Lassila, and J. Partanen, "Application of Low Voltage DC-Distribution System - A Techno-Economical Study,” 19th International Conference on Electricity Distribution, 2007.

[2] T. Kaipia, P. Peltoniemi, and J. Lassila, P, "Impact of low voltage DC system on reliability of electricity distribution,” CIRED 2009 conference, 2009.

[3] M. Brenna, E. Tironi, and G. Ubezio, "Proposal of a local DC distribution network with distributed energy resources,” 2004 11th International Conference on Harmonics and Quality of Power (IEEE Cat. No.04EX951), 2004, pp. 397-402.

[4] P. Karlsson, "DC Distributed Power Systems Analysis, Design and Control for a Renewable Energy System,” Lund University, 2002.

[5] D. Nilsson, "DC Distribution Systems," CHALMERS UNIVERSITY OF TECHNOLOGY, 2005.

[6] A. Sannino and G. Postiglione, Math H.J. Bollen, "Feasibility of a DC network for Commercial Facilities,” IEEE Transactions on Industrial Applications, 2003.

[7] P. Jarventausta, J. Partanen, and S. Karkkainen, "Interactive customer interface for advanced distribution management and electricity market," SmartGrids for Distribution, 2008. IET-CIRED. CIRED Seminar, pp. 1-4.

[8] A. Lana, T. Lindh, and J. Partanen, "LVDC Power Distribution Network Concept: System Stability,” Power Systems Computation Conference, 2011.

[9] T. Vornanen, A. Mäkinen, P. Järventausta, A. Lana, T. Kaipia, and P. Nuutinen, "PSCAD MODELING AND SIMULATION OF LVDC DISTRIBUTION NETWORKS,” NORDAC 2009 conference, 2009. 